\title{
Effects of wearing a full body compression garment during recovery from an ultra-trail race
}

Recto running head : Effects of a full body compression garment following an ultra-trail race

Verso running head : I. Martínez-navarro et al.

Ignacio Martínez-Navarro ${ }^{1,2}$, (DInma Aparicio ${ }^{3,4}$, iD Jose Ignacio Priego Quesada ${ }^{3} \mathbf{1}$, iDPedro Pérez-Soriano ${ }^{3}$, Eladio Collado 5

, Barbara Hernando ${ }^{6}$, Carlos Hernando 7,8

${ }^{1}$ Physical Education and Sports Department, University of Valencia, Valencia, Spain

${ }^{2}$ Sports Health Unit, Valencia, Spain

${ }^{3}$ Research Group in Sports Biomechanics (GIBD), Physical Education and Sports Department, University of Valencia, Valencia, Spain

${ }^{4}$ AITEX (Textil Research Institute), Alcoy, Spain

${ }^{5}$ Faculty of Health Sciences, Jaume I University, Castellon, Spain

${ }^{6}$ Department of Medicine, Jaume I University, Castellon, Spain

${ }^{7}$ Sport Service, Jaume I University, Castellon, Spain

${ }^{8}$ Department of Education and Specific Didactics, Jaume I University, Castellon, Spain

Correspondence: Ignacio Martínez-Navarro, Faculty of Physical Activity and Sport Sciences, Department of Physical Education and Sports, University of Valencia, C/Gascó Oliag 3, Valencia 46010, Spain. Email: Ignacio.Martinez-Navarro@uv.es

Copyright Line: (c) 2020 European College of Sport Science

\section{Abstract}

In sport disciplines with high levels of muscle damage such as an ultra-trail competition, full body compression garments (FBCG) may have an ergogenic effect during the recovery process. The aim of the study was to assess the influence of FBCG worn for $24 \mathrm{~h}$ 
immediately after a 107-km ultra-trail on delayed onset muscle soreness (DOMS), muscle damage, inflammatory and renal response. Thirty-two athletes (19 males and 13 females; $\mathrm{VO}_{2 \text { peak }}: 54.1 \pm 5.2 \mathrm{ml} \mathrm{O} / \mathrm{kg} / \mathrm{min}$ ) participated in the study. The following blood markers were analysed before, immediately after, at 24 and $48 \mathrm{~h}$ post-race: lactate dehydrogenase, creatine kinase, Creactive protein and creatinine. The glomerular filtration rate was also calculated. Delayed onset muscle soreness was evaluated before, immediately after and at $24 \mathrm{~h}$ post-race. On arrival at the finishing line, athletes were randomised into one of two recovery groups (FBCG and control group). The results showed that wearing FBCG did not influence the evolution of any of the blood markers up to $48 \mathrm{~h}$ after the race $(p>.05)$. However, FBCG group presented a lower increase in posterior leg DOMS (11.0 \pm $46.2 \%$ vs $112.3 \pm 170.4 \%, p=.03, d=0.8$ ). Therefore, although FBCG is not useful for reducing muscle damage and inflammatory response after an ultra-trail race, its use may still be recommended as a recovery method to reduce muscle soreness [Q1].

Trial registration: ClinicalTrials.gov identifier: NCT03990259.

\author{
Keywords \\ - Musculoskeletal \\ - recovery \\ - biochemistry
}

\title{
FUNDING
}

This work was supported by the Valencia Regional Government through [Q3]IVACe, and co-granted by FEDER (Reference: IMDEEA/2019/53).

\section{Introduction}

Proper recovery following a competition enables the athlete to return to regular training earlier and, consequently, improves long-term performance (Richard \& Koehle, 2019). This fact has aroused the interest of both coaches and scientists regarding interventions aimed at optimising the recovery process(Kellmann et al., 2018). Different recovery interventions were assessed such as massage, stretching, cryotherapy, nutritional supplementation (i.e. branched-chain amino acids, anti-inflammatory drugs) or clothing with specific compressive qualities (Barnett, 2006). However, most studies have assessed the influence of the different interventions under laboratory conditions and research under real competition conditions is now required(Engel, Holmberg, $\&$ Sperlich, 2016).

Wearing compression garments during the recovery process has been one of the strategies most commonly analysed by different studies (Brown et al., 2017; Engel et al., 2016; Pérez-Soriano et al., 2019). Although Hill, Howatson, van Someren, Leeder, and Pedlar (2014) found that wearing lower limb compression tights for $72 \mathrm{~h}$ following a simulated road marathon had no significant effect on muscle damage and inflammatory markers, a reduction in delayed onset muscle soreness (DOMS) was observed. In this respect, recent reviews have suggested that the use of compression garments after running has little or no effect on muscle damage and inflammatory markers (Brown et al., 2017; Engel et al., 2016). However, most of the studies were performed using protocols to induce damage (e.g. series of sprints, drop-jumps or eccentric exercise) (Davies, Thompson, \& Cooper, 2009; Duffield, Cannon, \& King, 2010; Hill et al., 2017; Kim, Kim, \& Lee, 2017) or simulated trails, half-marathons and marathons (Bieuzen et al., 2014; Hill, Howatson, van Someren, Walshe \& Pedlar, 2014; McDonnell, Cooper, Mlinar, \& Mekjavic, 2018). In addition, the type of garment worn could have an influence on the ergogenic effect and most studies have only been undertaken on the use of compressive stockings or tights (Engel et al., 2016; Pérez-Soriano et al., 2019). The ergogenic effect of full body compression garments (FBCG) could be greater than compressive stockings or thighs due to the higher surface covered by the garment, so further studies with these types of garments after real competitions with high levels of muscle damage are required (Pérez-Soriano et al., 2019).

Ultra-trail running could well be a relevant sport to assess the possible beneficial effects of compression garments during recovery, since a very pronounced post-race increase in inflammation and muscle damage blood markers has been reported (Hoffman, Ingwerson, Rogers, Hew-Butler, \& Stuempfle, 2012; Millet et al., 2011). These high levels of inflammation and muscle damage are as a consequence of the succession of prolonged eccentric actions that occur in the downhill sections of these races (Giandolini, Horvais, et al., 2016; Giandolini, Vernillo, et al., 2016; Vernillo et al., 2017). An example of the levels of ultra-trail running damage is that while $1350 \mathrm{U} / \mathrm{l}$ of circulating levels of creatine kinase (CK) were observed after a protocol of 2 sets of 50 bicep curls with 12 maximal eccentric contractions (Brown et al., 2017), CK concentrations of over 15,000 U/I have been reported after ultra-trail races (i.e. Ultra Trail du Mont-Blanc or Western States Endurance Run) (Hoffman et al., 2012; Millet et al., 2011). Although several studies have analysed the effect of compression garments on DOMs, inflammatory and muscle damage markers following a simulated trail running (Bieuzen et al., 2014; McDonnell et al., 2018), there is a lack of research into their effect following ultra-trail races.

The aim of the study, therefore, was to analyse the effect on DOMS, muscle damage, inflammatory response and renal function of wearing a FBCG for $24 \mathrm{~h}$ immediately after a 107-km ultra-trail. We hypothesised that, in this extreme context, the FBCG would 


\section{Methods}

\subsection{Participants}

Forty-seven recreational ultra-endurance athletes (29 males and 18 females) were recruited to participate in the study. This research was undertaken at the Penyagolosa Trails CSP race in 2019 (Spain). The track consisted of $107.4 \mathrm{~km}$, starting at an altitude of $40 \mathrm{~m}$ and finishing at $1280 \mathrm{~m}$ above sea level, with a total positive and negative elevation of 5604 and $4356 \mathrm{~m}$, respectively. All subjects were informed of the procedure and gave their written consent to participate. They were also allowed to withdraw from the study voluntarily. A questionnaire was used to collect demographic information as well as training and competition history. Participants were also subjected to a cardiopulmonary exercise test and a body composition assessment (Tanita BC-780MA, Tanita Corp., Tokyo, Japan) between 2 and 4 weeks prior to the race. The investigation was conducted according to the Declaration of Helsinki and approval for the project was obtained from the research Ethics Committee of the University Jaume I of Castellon (Expedient Number CD/007/2019). This study is enrolled in the ClinicalTrails.gov database, with code number NCT03990259 (www.clinicaltrials.gov).

From the initial sample (47 athletes), 4 participants did not start the race due to injury and 32 athletes successfully completed the race with an average finishing time of $21 \mathrm{~h} 23 \mathrm{~min} \pm 3 \mathrm{~h} 28 \mathrm{~min}$. The finisher/starter ratio for the subjects of the present study (i.e. 74.4\%) was similar to the ratio when all race participants were considered (73.8\%), whereas the average finish time was somewhat faster when all race participants were considered ( $20 \mathrm{~h} 24 \mathrm{~min} \pm 3 \mathrm{~h} 11 \mathrm{~min}$ ).

\subsection{Full body compression garments}

Participants were randomised on their arrival at the finishing line into one of two recovery groups: (1) experimental group (FBCG), wearing FBCG during the first $24 \mathrm{~h}$ following the race (thus including night sleep); and (2) control group (CG), not wearing any compressive garments for the immediate $24 \mathrm{~h}$ following the race. Both groups were asked to abstain from doing any exercise during the first $48 \mathrm{~h}$ post-race period. In addition, massage and use of electromyostimulation were neither allowed during this time period. A follow-up online questionnaire was employed to verify that athletes did not use other recovery procedures during the first $48 \mathrm{~h}$ post-race. Each recovery group was then formed by 16 participants (FBCG: 8 men and 8 women; CG: 11 men and 5 women). The average finishing times of FBCG and CG were $21 \mathrm{~h} 11 \mathrm{~min} \pm 3 \mathrm{~h} 14 \mathrm{~min}$ and $21 \mathrm{~h} 33 \mathrm{~min} \pm 3 \mathrm{~h} 47 \mathrm{~min}$ respectively $(p=0.71 ; d=0.1)$. The characteristics of FBCG and CG participants are presented in Table I.

Table I. Characteristics of FBCG and CG participants (mean \pm SD)

\begin{tabular}{|c|c|c|c|c|c|}
\hline & \multirow[b]{2}{*}{ Whole sample $(n=32)$} & \multirow[b]{2}{*}{$\mathrm{FBCG}(n=16)$} & \multirow[b]{2}{*}{ CG $(n=16)$} & \multicolumn{2}{|c|}{ FBCG vs. CG } \\
\hline & & & & $p$-value & Cohen's D \\
\hline Age (years) & $41 \pm 6$ & $41 \pm 6$ & $41 \pm 6$ & 0.66 & 0.2 \\
\hline BMI $\left(\mathrm{kg} / \mathrm{m}^{2}\right)$ & $22.8 \pm 2.0$ & $22.5 \pm 1.9$ & $23.2 \pm 2.1$ & 0.33 & 0.4 \\
\hline FM (\%) & $15.4 \pm 4.9$ & $15.7 \pm 4.7$ & $15.1 \pm 5.2$ & 0.70 & 0.1 \\
\hline LBM (\%) & $80.3 \pm 4.7$ & $79.9 \pm 4.5$ & $80.7 \pm 5.1$ & 0.66 & 0.2 \\
\hline $\mathrm{VO}_{2 \text { peak }}(\mathrm{ml} \mathrm{O} / \mathrm{kg} / \mathrm{min})$ & $54.1 \pm 5.2$ & $53.2 \pm 4.2$ & $54.9 \pm 6.0$ & 0.38 & 0.3 \\
\hline$V_{\text {MAX }}(\mathrm{km} / \mathrm{h})$ & $15.9 \pm 1.9$ & $15.9 \pm 2.0$ & $15.9 \pm 1.8$ & 0.92 & 0.0 \\
\hline$V_{\text {VT2 }}(\mathrm{km} / \mathrm{h})$ & $13.3 \pm 1.4$ & $13.3 \pm 1.4$ & $13.3 \pm 1.4$ & 0.99 & 0.0 \\
\hline Number of years running & $8 \pm 3$ & $8 \pm 3$ & $7 \pm 3$ & 0.74 & 0.1 \\
\hline Number of races $>100 \mathrm{~km}$ & $2 \pm 3$ & $3 \pm 3$ & $2 \pm 3$ & 0.78 & 0.1 \\
\hline Weekly training days & $5 \pm 1$ & $5 \pm 1$ & $5 \pm 1$ & 0.65 & 0.2 \\
\hline Weekly running volume (km) & $70 \pm 22$ & $71 \pm 18$ & $69 \pm 26$ & 0.80 & 0.1 \\
\hline Weekly positive elevation (m) & $1772 \pm 691$ & $1650 \pm 475$ & $1894 \pm 854$ & 0.33 & 0.4 \\
\hline
\end{tabular}




\begin{tabular}{|l|l|l|l|l|l|}
\hline Weekly training hours & $10 \pm 4$ & $11 \pm 4$ & $8 \pm 4$ & 0.10 & 0.6 \\
\hline Strength training (\%) & $81.3 \%$ & $93.8 \%$ & $68.8 \%$ & 0.07 & - \\
\hline
\end{tabular}

Note: BMI, Body Mass Index; FM, fat mass; LBM, lean body mass; $V_{2}$ peak, peak oxygen uptake; $V_{M A x}$, peak speed reached at the Cardiopulmonar Exercise Test; $V_{\mathrm{VT} 2}$, speed associated with the second ventilatory threshold in the Cardiopulmonar Exercise Test; Strength training (\%), percentage of participants who performed at least one weekly strength-training in the previous 3 months.

The composition of the FBCG was $88 \%$ polyamide and $12 \%$ elastane, weighing $345 \mathrm{~g}$, and with a graduated compression of $10-$ $15 \mathrm{mmHg}$ according to the manufacturer's specifications and validated at the Textile Research Institute (AITEX, Spain) using Medical Stocking Tester technology (model MST MK IV, Salzmann Group, Switzerland).

\subsection{Blood sampling and analysis}

Blood samples were collected from an antecubital vein by venipuncture the day before the race, after crossing the finishing line, 24 and $48 \mathrm{~h}$ post-race using BD Vacutainer PST II tubes. Samples were centrifuged at $3500 \mathrm{rpm}$ for ten minutes and kept at $4{ }^{\circ} \mathrm{C}$ during transport to Vithas Rey Don Jaime Hospital (Castellon, Spain), where they were processed using the modular platform Roche / Hitachi clinical chemistry analyser Cobas c311 (Roche Diagnostics, Penzberg, Germany), as previously published (BernatAdell et al., 2019; Panizo Gonzalez et al., 2019). Lactate dehydrogenase (LDH) and CK were used as muscle damage markers, Creactive protein (CRP) as an indicator of acute inflammatory reaction, and creatinine as a marker of renal function. The Chronic Kidney Disease Epidemiology Collaboration (CKD-EPI) equation was used to calculate the glomerular filtration rate (GFR) (Levey et al., 2009). Biochemical results obtained immediately post-race were adjusted by employing the Dill and Costill method (Dill \& Costill, 1974), using haematocrit and haemoglobin to determine the magnitude of plasma volume changes after the race in each participant (Alis et al., 2015; Dill \& Costill, 1974).

\subsection{Muscle soreness}

DOMS was recorded using a visual analogue scale (VAS) the day before the race, within 10 min after crossing the finishing line and $24 \mathrm{~h}$ post-race. The VAS consisted of a $10-\mathrm{cm}$ horizontal line, the endpoints of which were labelled as 'no pain' $(0 \mathrm{~cm})$ and 'extreme pain' (10 cm). The VAS, has been shown to be valid and reliable in previous research (Cleather \& Guthrie, 2007), and is commonly used to detect DOMS (Nakagawa et al., 2018; Tojima, Noma, \& Torii, 2016; Wiewelhove et al., 2018). Participants were asked to palpate four different lower limb regions (anterior knee, DOMS_AK; posterior knee, DOMS_PK; anterior leg, DOMS_AL; posterior leg, DOMS_PL) and then mark a vertical line at the point on the scale that best represented the amount of muscle pain at the time of the measurement. A global value (DOMS_G) was also recorded as an overall participant perception of full body muscle pain. Scores were determined from the distance in $\mathrm{cm}$ from the left border of the scale to the point marked (Cleather $\&$ Guthrie, 2007).

\subsection{Statistical analysis}

Statistical analyses were carried out using the Statistical Package for the Social Sciences software (IBM SPSS Statistics for Windows, version 22.0, IBM Corp., Armonk, NY, USA). Normality of the data was confirmed using Kolmogorov Smirnov test ( $p$ > .05). A two-factor repeated-measures ANOVA was conducted, with one between-subject factor ('Intervention'; FBCG vs CG) and one within-subject factor ('Time'; PRE, POST, 24 and 48 h post-race), to assess the possible effect of wearing FBCG on analytical variables. The same procedure was employed to appraise possible differences in DOMS between the above-mentioned groups. Whenever Mauchly's Sphericity test was violated, necessary technical corrections were performed using the Greenhouse-Geisser test; and for each ANOVA, if a significant main effect or interaction was identified, Bonferroni post-hoc comparisons were conducted. Moreover, DOMS and analytical values at $24 \mathrm{~h}$ and analytical values at $48 \mathrm{~h}$ following the race, set as percentages of post-race values, were compared between groups using unpaired Student's t-tests. In addition, the meaningfulness of the outcomes was estimated through the partial estimated effect size ( $\eta^{2}$ partial) for ANOVA and Cohen's $d$ effect size for pairwise comparisons. Cohen's $D<0.5$ was considered small; between 0.5 and 0.8 , moderate; and greater than 0.8, large (Cohen, 1988). The significance level was set at $p$-value $<.05$ and data are presented as means and standard deviations ( \pm SD).

\section{Results}

Univariate contrast analysis showed a significant effect for 'Time' on creatinine $\left[F=73.28 ; p<0.01 ; \eta^{2}\right.$ partial $\left.=0.71\right]$, GFR $\left[F=88.66 ; p<.01 ; \eta^{2}\right.$ partial $\left.=0.75\right]$, CK $\left[F=34.49 ; p<.01 ; \eta^{2}\right.$ partial $\left.=0.53\right]$, LDH $\left[F=61.28 ; p<.01 ; \eta^{2}\right.$ partial $\left.=0.67\right]$ and CRP $\left[F=57.22 ; p<.01 ; \eta^{2}\right.$ partial $\left.=0.66\right]$. No 'Intervention $\mathrm{x}$ Time' interaction effects were revealed for the analytical variables (see Table II) and Student's $t$-tests also presented no differences between FBCG and CG.

Table II. Analytical variables in FBCG and CG (mean \pm SD) 


\begin{tabular}{|c|c|c|c|c|}
\hline & \multirow[b]{2}{*}{$\operatorname{FBCG}(n=16)$} & \multirow[b]{2}{*}{ CG $(n=16)$} & \multicolumn{2}{|c|}{ FBCG vs. CG } \\
\hline & & & $p$-value & Cohen's D \\
\hline Pre-race cretinine (mg/dL) & $1.0 \pm 0.2$ & $1.0 \pm 0.1$ & 0.62 & 0.2 \\
\hline Post-race cretinine (mg/dL) & $1.3 \pm 0.4^{\mathrm{a}}$ & $1.3 \pm 0.2^{\mathrm{a}}$ & 1.00 & 0.0 \\
\hline $24 \mathrm{~h}$ post-race cretinine $(\mathrm{mg} / \mathrm{dL})$ & $1.0 \pm 0.2^{b}$ & $1.0 \pm 0.2^{b}$ & 1.00 & 0.0 \\
\hline $48 \mathrm{~h}$ post-race cretinine (mg/dL) & $0.9 \pm 0.2^{c}$ & $0.9 \pm 0.1^{c}$ & 0.83 & 0.1 \\
\hline Pre-race GFR (mL/min/1.73 m²) & $73.6 \pm 7.7$ & $75.6 \pm 8.6$ & 0.48 & 0.3 \\
\hline Post-race GFR (mL/min/1.73 m²) & $54.2 \pm 12.4^{\mathrm{a}}$ & $55.4 \pm 10.1^{\mathrm{a}}$ & 0.76 & 0.1 \\
\hline $24 \mathrm{~h}$ post-race GFR (mL/min/1.73 $\left.\mathrm{m}^{2}\right)$ & $71.9 \pm 15.6^{b}$ & $74.3 \pm 11.6^{\mathrm{b}}$ & 0.62 & 0.2 \\
\hline $48 \mathrm{~h}$ post-race GFR ( $\left.\mathrm{mL} / \mathrm{min} / 1.73 \mathrm{~m}^{2}\right)$ & $82.1 \pm 17.1^{c}$ & $82.5 \pm 8.5^{c}$ & 0.93 & 0.0 \\
\hline Pre-race CK (UI/L) & $179.6 \pm 110.2$ & $227.8 \pm 294.9$ & 0.55 & 0.2 \\
\hline Post-race CK (UI/L) & $4231.6 \pm 2680.0^{a}$ & $5728.5 \pm 5007.7^{\mathrm{a}}$ & 0.30 & 0.4 \\
\hline 24 h post-race CK (UI/L) & $2561.6 \pm 2290.7^{a}$ & $2812.9 \pm 2647.0^{\mathrm{a}, \mathrm{b}}$ & 0.78 & 0.1 \\
\hline 48 h post-race CK (UI/L) & $1425.1 \pm 1671.2^{\mathrm{a}, \mathrm{c}}$ & $1451.1 \pm 1710.0^{\mathrm{a}, \mathrm{c}}$ & 0.97 & 0.0 \\
\hline Pre-race LDH (UI/L) & $196.5 \pm 31.0$ & $182.4 \pm 30.8$ & 0.21 & 0.5 \\
\hline Post-race LDH (UI/L) & $361.6 \pm 81.5^{a}$ & $391.2 \pm 133.3^{\mathrm{a}}$ & 0.46 & 0.3 \\
\hline 24 h post-race LDH (UI/L) & $318.5 \pm 96.4^{a, b}$ & $325.7 \pm 131.0^{a, b}$ & 0.86 & 0.1 \\
\hline 48 h post-race LDH (UI/L) & $304.3 \pm 105.1^{\mathrm{a}}$ & $320.0 \pm 146.3^{a}$ & 0.73 & 0.1 \\
\hline Pre-race CRP (mg/dL) & $0.2 \pm 0.6$ & $0.1 \pm 0.1$ & 0.44 & 0.3 \\
\hline Post-race CRP (mg/dL) & $2.0 \pm 1.4^{\mathrm{a}}$ & $2.0 \pm 1.1^{\mathrm{a}}$ & 0.97 & 0.0 \\
\hline $24 \mathrm{~h}$ post-race $\mathrm{CRP}(\mathrm{mg} / \mathrm{dL})$ & $3.9 \pm 2.7^{a, b}$ & $3.7 \pm 2.4^{\mathrm{a}, \mathrm{b}}$ & 0.79 & 0.1 \\
\hline $48 \mathrm{~h}$ post-race CRP (mg/dL) & $1.9 \pm 1.3^{\mathrm{a}, \mathrm{c}}$ & $1.9 \pm 1.2^{a, c}$ & 0.98 & 0.0 \\
\hline
\end{tabular}

Note: GFR, Glomerular filtration rate; CK, Creatine kinase; LDH, Lactate dehydrogenase; CRP, C-reactive protein.

asignificantly different from pre-race value.

bSignificantly different from post-race value.

cSignificantly different from $24 \mathrm{~h}$ post-race value.

Regarding DOMS values, univariate contrast analysis showed a significant effect for 'Time' on DOMS_G $\left[F=36.22 ; p<.01 ; \eta^{2}\right.$ partial $=0.55]$, DOMS_AK $\left[F=21.84 ; p<.01 ; \eta^{2}\right.$ partial $\left.=0.42\right]$, DOMS_PK $\left[F=6.84 ; p<.01 ; \eta^{2}\right.$ partial $\left.=0.19\right]$, DOMS_AL $[F=12.33$; $p<.01 ; \eta^{2}$ partial $\left.=0.29\right]$ and DOMS_PL $\left[F=5.06 ; p=0.015 ; \eta^{2}\right.$ partial $\left.=0.14\right]$. No 'Intervention $\times$ Time' interaction effects were revealed for DOMS variables; however, Student's t-tests revealed that FBCG showed a smaller increase in DOMS_PL $24 \mathrm{~h}$ post-race $(11.0 \pm 46.2 \%$ vs $11.3 \pm 170.4 \%, p=.03, d=0.8)$ (see Figure 1 ).

Figure 1. Relative changes $24 \mathrm{~h}$ post-race in DOMS variables between FBCG and CG. * Significant difference between groups $(p<.05)$. 


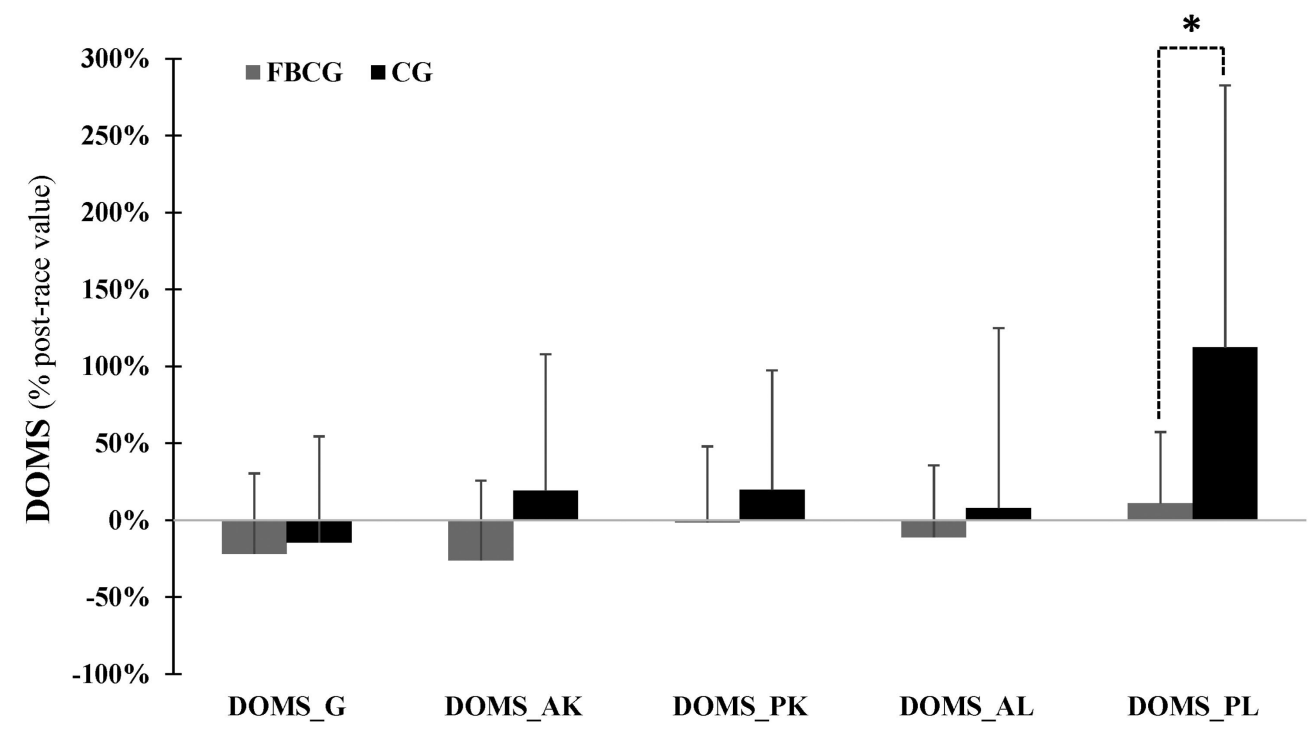

\section{Discussion}

The present study analysed the effect on DOMS, muscle damage, inflammatory response and renal function of wearing FBCG for $24 \mathrm{~h}$ immediately following a 107-km ultra-trail. It was hypothesised that runners wearing FBCG for the initial $24 \mathrm{~h}$ post-race period would present less DOMS and muscle damage, and better inflammation recovery. However, although better recovery from DOMS in posterior leg among the runners who used FBCG was observed, no effect was found on muscle damage, inflammatory and renal function recovery.

Kraemer et al. (2001, 2010) suggested two possible mechanisms as to why compression garments might reduce the concentration of muscle damage markers: (a) the release of damage markers would be lessened as a result of compression treatment, and (b) compression would facilitate the clearance and removal of myofibrillar proteins. However, most previous studies assessing the use of compression garments during recovery have shown no significant effect on muscle damage markers (Bieuzen et al., 2014; Duffield et al., 2010; Goto \& Morishima, 2014; Goto, Mizuno, \& Mori, 2017; Hill et al., 2017; Hill, Howatson, van Someren, Walshe, et al., 2014; Jakeman, Byrne, \& Eston, 2010; Kim et al., 2017; Mizuno, Morii, Tsuchiya, \& Goto, 2016). It has been suggested that their effectiveness could be dependent on the magnitude of post-exercise CK and LDH concentration (Brown et al., 2017). In addition, the need for further studies using different compressive garments, such as stockings or tights, was recommended (PérezSoriano et al., 2019). Hence, considering that downhill sections in ultra-trail races involve a succession of prolonged eccentric actions (Giandolini, Horvais, et al., 2016; Giandolini, Vernillo, et al., 2016; Vernillo et al., 2017) and large CK and LDH values have been reported following those races (Hoffman et al., 2012; Millet et al., 2011), we hypothesised that using FBCG during recovery would reduce muscle damage response. However, wearing FBCG after the race had no influence on the response in these markers. Consequently, our results do not support the hypothesis proposed by Kraemer et al. $(2001 ; 2010)$.

On the other hand, compression garments have also been proposed to reduce the swelling and inflammatory processes associated with muscle damage (Kraemer, French, \& Spiering, 2004). Indeed, it has been suggested that the garments work by creating an external pressure gradient and reducing the space available for swelling to occur, thus minimising the secondary inflammatory response (Davies et al., 2009). However, our results did not observe any reduction in CRP in those runners who wore FBCG during post-race recovery. Moreover, this finding is in line with the most recent studies in the field (Bieuzen et al., 2014; Duffield et al., 2010; Goto et al., 2017; Goto \& Morishima, 2014; Hill et al., 2017; Hill, Howatson, van Someren, Leeder, et al., 2014; Kim et al., 2017; Mizuno et al., 2016). It has also been suggested that the use of compression garments can improve hemodynamics following vigorous exercise (Born, Sperlich, \& Holmberg, 2013) and that exercise-induced renal alterations have been associated with mechanisms of inflammatory origin (Panizo Gonzalez et al., 2019). Our results, nevertheless, did not show any effect of FBCG on creatinine and GFR, and, therefore, no improvement on the recovery of renal function can be suggested. In either case, the fact that both blood markers were normalised within $24 \mathrm{~h}$ after the race suggests that no long-term renal function repercussions are expected.

The results of the our study present a positive effect of FBCG on DOMS. Moreover, the lower limb regions where the ergogenic effect was observed ( $p=.03$ for the posterior limb; $p=.08$ for the anterior knee, not mentioned in results section) are those that have been reported to suffer greater neuromuscular fatigue following Ultra-trail races (Millet et al., 2011). This result is in agreement with previous studies using compression garments, following protocols to induce muscle damage (Davies et al., 2009; Duffield et al., 2010; Goto \& Morishima, 2014; Jakeman et al., 2010; Kim et al., 2017; Kraemer et al., 2010) and endurance workouts (Hill, Howatson, van Someren, Walshe, et al., 2014; McDonnell et al., 2018). In this respect, the meta-analyses review by Hill, Howatson, van Someren, Leeder et al. (2014) revealed that, with the use of compression garments, $66 \%$ of the population is likely 
to experience reduced DOMS. Some authors have argued that applying compression garments during recovery from muscledamaging exercise enhances lymphatic outflow, thereby leading to less muscle swelling and pain and greater comfort (Born et al., 2013; Davies et al., 2009; Kraemer et al., 2001). Despite this hypothesis, the possibility that the effect upon perceived muscle soreness is influenced by more positive perceptions and participants' intuitions concerning the results to be expected cannot ever be excluded (placebo effect). Indeed, a previous study that analysed the effect of compression socks worn during the recovery between repeated maximal running bouts observed that their ergogenic effect was further enhanced when athletes believe in its efficacy (Brophy-Williams, Driller, Kitic, Fell, \& Halson, 2017).

\section{Conclusions}

The use of FBCG for $24 \mathrm{~h}$ following an ultra-trail reduces posterior leg DOMS, but has no influence on muscle damage, inflammatory response and renal function markers. Therefore, the positive and negative aspects of using FBCG during the recovery process have to be weighed up. Coaches may recommend wearing FBCG to their athletes during the recovery process for the benefits they present in reducing DOMS, especially to those runners who often complain of greater muscle soreness in the posterior leg region following Ultra-trail races. However, for some athletes, wearing FBCG during recovery can be uncomfortable due to pressure and thermal discomfort. In these cases, it is not recommendable to insist on wearing such garments, as they have no effect on muscle damage and inflammatory markers.

The main limitation of this study was the possible placebo effect of FBCG on DOMS. Future studies, therefore, could use a control condition (full garment without compression). In addition, future studies could explore other physiological (e.g. oxidative stress) and physical variables (e.g. counter-movement jump test).

\section{Acknowledgements}

This research was carried out thanks to the collaboration of the Vithas Hospitals group, Penyagolosa Trails and Catedra Endavant Villarreal CF de l'Esport. Authors are also grateful to all the staff involved in the organisation of the race and all runners and volunteers participating in this study. In addition, the study has been undertaken with the collaboration of Aitex (Textile Research Institute) that provided the FBCG and is involved in the TPTex project, supported by the Valencia Regional Government through IVACe, and co-granted by FEDER (Reference: IMDEEA/2019/53). The sponsors had no involvement in the study design, data collection, analysis and interpretation, writing of the manuscript or the decision to submit the paper for publication.

\section{Disclosure statement}

No potential conflict of interest was reported by the author(s [Q4]).

\section{ORCID}

Inma Aparicio http://orcid.org/0000-0003-3784-8489

Jose Ignacio Priego Quesada http://orcid.org/0000-0002-0375-1454

Pedro Pérez-Soriano http://orcid.org/0000-0002-9825-3801

\section{References}

Alis, R., Sanchis-Gomar, F., Primo-Carrau, C., Lozano-Calve, S., Dipalo, M., Aloe, R., ... Lippi, G. (2015). Hemoconcentration induced by exercise: Revisiting the Dill and Costill equation. Scandinavian Journal of Medicine \& Science in Sports, 25(6), e630-e637. doi:10.1111/sms.12393

Barnett, A. (2006). Using recovery modalities between training sessions in elite athletes: Does it help? Sports Medicine, 36(9), 781-796. doi:10.2165/00007256-200636090-00005

Bernat-Adell, M. D., Collado-Boira, E. J., Moles-Julio, P., Panizo-Gonzalez, N., Martinez-Navarro, I., Hernando-Fuster, B., \& Hernando-Domingo, C. (2019). Recovery of inflammation, cardiac, and muscle damage biomarkers after running a marathon. Journal of Strength and Conditioning Research. doi:10.1519/JSC.0000000000003167

Bieuzen, F., Brisswalter, J., Easthope, C., Vercruyssen, F., Bernard, T., \& Hausswirth, C. (2014). Effect of wearing compression stockings on recovery after mild exercise-induced muscle damage. International Journal of Sports Physiology and Performance, 9(2), 256-264. doi:10.1123/ijspp.2013-0126

Born, D. P., Sperlich, B., \& Holmberg, H. C. (2013). Bringing light into the dark: Effects of compression clothing on performance and recovery. International Journal of Sports Physiology and Performance, 8(1), 4-18.

Brophy-Williams, N., Driller, M. W., Kitic, C. M., Fell, J. W., \& Halson, S. L. (2017). Effect of compression socks worn between repeated maximal running bouts. International Journal of Sports Physiology and Performance, 12(5), 621-627. 
doi:10.1123/ijspp.2016-0162

Brown, F., Gissane, C., Howatson, G., van Someren, K., Pedlar, C., \& Hill, J. (2017). Compression garments and recovery from exercise: A meta-analysis. Sports Medicine, 47(11), 2245-2267. doi:10.1007/s40279-017-0728-9

Cleather, D. J., \& Guthrie, S. R. (2007). Quantifying delayed-onset muscle soreness: A comparison of unidimensional and multidimensional instrumentation. Journal of Sports Sciences, 25(8), 845-850. doi:10.1080/02640410600908050

Cohen, J. (1988). Statistical power analysis for the behavioral sciences. Hillsdale: Lawrence Erlbaum.

Davies, V., Thompson, K. G., \& Cooper, S. M. (2009). The effects of compression garments on recovery. Journal of Strength and Conditioning Research, 23(6), 1786-1794. doi:10.1519/JSC.0b013e3181b42589

Dill, D. B., \& Costill, D. L. (1974). Calculation of percentage changes in volumes of blood, plasma, and red cells in dehydration. Journal of Applied Physiology, 37(2), 247-248. doi:10.1152/jappl.1974.37.2.247

Duffield, R., Cannon, J., \& King, M. (2010). The effects of compression garments on recovery of muscle performance following high-intensity sprint and plyometric exercise. Journal of Science and Medicine in Sport, 13(1), 136-140.

doi:10.1016/j.jsams.2008.10.006

Engel, F. A., Holmberg, H. C., \& Sperlich, B. (2016). Is there evidence that runners can benefit from wearing compression clothing? Sports Medicine, 46(12), 1939-1952. doi:10.1007/s40279-016-0546-5

Giandolini, M., Horvais, N., Rossi, J., Millet, G. Y., Morin, J. B., \& Samozino, P. (2016). Acute and delayed peripheral and central neuromuscular alterations induced by a short and intense downhill trail run. Scandinavian Journal of Medicine \& Science in Sports, 26(11), 1321-1333. doi:10.1111/sms.12583

Giandolini, M., Vernillo, G., Samozino, P., Horvais, N., Edwards, W. B., Morin, J. B., \& Millet, G. Y. (2016). Fatigue associated with prolonged graded running. European Journal of Applied Physiology, 116(10), 1859-1873. doi:10.1007/s00421-016-3437-4

Goto, K., Mizuno, S., \& Mori, A. (2017). Efficacy of wearing compression garments during post-exercise period after two repeated bouts of strenuous exercise: A randomized crossover design in healthy, active males. Sports Medicine - Open, 3(1), 25. doi:10.1186/s40798-017-0092-1

Goto, K., \& Morishima, T. (2014). Compression garment promotes muscular strength recovery after resistance exercise. Medicine \& Science in Sports \& Exercise, 46(12), 2265-2270. doi:10.1249/MSS.0000000000000359

Hill, J., Howatson, G., van Someren, K., Gaze, D., Legg, H., Lineham, J., \& Pedlar, C. (2017). The effects of compressiongarment pressure on recovery after strenuous exercise. International Journal of Sports Physiology and Performance, 12(8), $1078-1084$. doi:10.1123/ijspp.2016-0380

Hill, J., Howatson, G., van Someren, K., Leeder, J., \& Pedlar, C. (2014). Compression garments and recovery from exerciseinduced muscle damage: A meta-analysis. British Journal of Sports Medicine, 48(18), 1340-1346. doi:10.1136/bjsports-2013-092456

Hill, J., Howatson, G., van Someren, K., Walshe, I., \& Pedlar, C. (2014). Influence of compression garments on recovery after marathon running. Journal of Strength and Conditioning Research, 28(8), 2228-2235. doi:10.1519/JSC.0000000000000469

Hoffman, M. D., Ingwerson, J. L., Rogers, I. R., Hew-Butler, T., \& Stuempfle, K. J. (2012). Increasing creatine kinase concentrations at the 161-km western states endurance run. Wilderness \& Environmental Medicine, 23(1), 56-60. doi:10.1016/j.wem.2011.11.001

Jakeman, J. R., Byrne, C., \& Eston, R. G. (2010). Lower limb compression garment improves recovery from exercise-induced muscle damage in young, active females. European Journal of Applied Physiology, 109(6), 1137-1144. doi:10.1007/s00421-010-14640

Kellmann, M., Bertollo, M., Bosquet, L., Brink, M., Coutts, A. J., Duffield, R., ... Beckmann, J. (2018). Recovery and performance in sport: Consensus statement. International Journal of Sports Physiology and Performance, 13(2), $240-245$. doi:10.1123/ijspp.2017-0759

Kim, J., Kim, J., \& Lee, J. (2017). Effect of compression garments on delayed-onset muscle soreness and blood inflammatory markers after eccentric exercise: A randomized controlled trial. Journal of Exercise Rehabilitation, 13(5), 541-545. doi:10.12965/jer.1735088.554

Kraemer, W. J., Bush, J. A., Wickham, R. B., Denegar, C. R., Gomez, A. L., Gotshalk, L. A., ... Putukian, M. (2001). Continuous compression as an effective therapeutic intervention in treating eccentric-exercise-induced muscle soreness. Journal of Sport Rehabilitation, 10(1), 11-23.

Kraemer, W. J., Flanagan, S. D., Comstock, B. A., Fragala, M. S., Earp, J. E., Dunn-Lewis, C., ... Maresh, C. M. (2010). Effects of a whole body compression garment on markers of recovery after a heavy resistance workout in men and women. Journal of Strength and Conditioning Research, 24(3), 804-814. doi:10.1519/JSC.0b013e3181d33025 
Kraemer, W. J., French, D. N., \& Spiering, B. A. (2004). Compression in the treatment of acute muscle injuries in sport. International SportMed Journal, 5(3), 200-208.

Levey, A. S., Stevens, L. A., Schmid, C. H., Zhang, Y. L., Castro, A. F., Feldman, H. I., ... Ckd, E. P. I. (2009). A new equation to estimate glomerular filtration rate. Annals of Internal Medicine, 150(9), 604-612. doi:10.7326/0003-4819-150-9-200905050-00006

McDonnell, A. C., Cooper, D., Mlinar, T., \& Mekjavic, I. B. (2018). The effect of post-exercise application of either graduated or uniform compression socks on the mitigation of delayed onset muscle soreness. Textile Research Journal. doi:10.1177/0040517518780002

Millet, G. Y., Tomazin, K., Verges, S., Vincent, C., Bonnefoy, R., Boisson, R. C., ... Martin, V. (2011). Neuromuscular consequences of an extreme mountain ultra-marathon. PLoS One, 6(2), e17059. doi:10.1371/journal.pone.0017059

Mizuno, S., Morii, I., Tsuchiya, Y., \& Goto, K. (2016). Wearing compression garment after endurance exercise promotes recovery of exercise performance. International Journal of Sports Medicine, 37(11), 870-877. doi:10.1055/s-0042-106301

Nakagawa, K., Inami, T., Yonezu, T., Kenmotsu, Y., Narita, T., Kawakami, Y., \& Kanosue, K. (2018). Unstable rocker shoes promote recovery from marathon-induced muscle damage in novice runners. Scandinavian Journal of Medicine \& Science in Sports, 28(2), 621-629. doi:10.1111/sms.12911

Panizo Gonzalez, N., Reque Santivanez, J. E., Hernando Fuster, B., Collado Boira, E. J., Martinez-Navarro, I., Chiva Bartoll, O., \& Hernando Domingo, C. (2019). Quick recovery of renal alterations and inflammatory activation after a marathon. Kidney Diseases, 5(4), 259-265. doi:10.1159/000500510

Pérez-Soriano, P., Sanchis-Sanchis, R., Jimenez-Perez, I., Gil-Calvo, M., Priego-Quesada, J., \& Aparicio, I. (2019). Compression garments in sport. In Materials in sports equipment (pp. 487-520). Elsevier.[Q5]

Richard, N. A., \& Koehle, M. S. (2019). Optimizing recovery to support multi-evening cycling competition performance. European Journal of Sport Science, 19(6), 811-823. doi:10.1080/17461391.2018.1560506

Tojima, M., Noma, K., \& Torii, S. (2016). Changes in serum creatine kinase, leg muscle tightness, and delayed onset muscle soreness after a full marathon race. Journal of Sports Medicine and Physical Fitness, 56(6), 782-788.

Vernillo, G., Giandolini, M., Edwards, W. B., Morin, J. B., Samozino, P., Horvais, N., \& Millet, G. Y. (2017). Biomechanics and physiology of uphill and downhill running. Sports Medicine, 47(4), 615-629. doi:10.1007/s40279-016-0605-y

Wiewelhove, T., Schneider, C., Doweling, A., Hanakam, F., Rasche, C., Meyer, T., ... Ferrauti, A. (2018). Effects of different recovery strategies following a half-marathon on fatigue markers in recreational runners. PLoS One, 13(11), e0207313. doi:10.1371/journal.pone.0207313 